\title{
IMPACT OF MYCORRHIZAL COLONISATION ON GRAPEVINE ESTABLISHMENT IN CYLINDROCARPON INFESTED SOIL
}

\author{
C.M. BLEACH, R.J. COPE, E.E. JONES, H.J. RIDGWAY \\ and M.V. JASPERS
}

\begin{abstract}
Bio-Protection and Ecology Division, Lincoln University, PO Box 84, Lincoln 7647, New Zealand
\end{abstract}

Corresponding author: bleachc2@lincoln.ac.nz.

\begin{abstract}
The effects of arbuscular mycorrhizae (AM), Glomus mosseae and Acaulospora laevis, on growth of six grape rootstock varieties and their infection by Cylindrocarpon species were investigated in a greenhouse experiment that challenged the mycorrhizal plants with a mixed inoculum of $C y$ lindrocarpon spp. Both species of AM had beneficial effects $(\mathrm{P}<0.05)$ on rootstock growth but this effect was specific for particular rootstock and AM combinations. Generally, G. mosseae had a more consistent positive effect and A. laevis was the only species to decrease plant growth in some rootstock varieties. Subsequently, two field trials conducted in Auckland and Blenheim used a mixture of the two AM species and two rootstock varieties. After 9 months, compared to control plants mycorrhizal plants had similar incidence of Cylindrocarpon infection at both sites $(\mathrm{P}>0.05)$, but greater root dry weights in Auckland (214\%; $\mathrm{P}<0.05$ ) and Blenheim (only $22 \% ; \mathrm{P}>0.05$ ). G. mosseae clearly has potential for improving health and growth of young grapevine plants. Keywords: mycorrhizal, Glomus mosseae, Acaulospora laevis, colonisation, Cylindrocarpon, black foot disease, grapevines, rootstocks.
\end{abstract}

\section{INTRODUCTION}

Cylindrocarpon black foot (BF) disease of grapevines (Vitis spp.) has been identified as a major cause of death of young vines in South Africa, North and South America, Australia, New Zealand and several Mediterranean countries in the last 5-10 years. Three species of Cylindrocarpon Wollenw., C. destructans (Zinnsm.) Scholten, C. macrodidymum Schroers, Halleen \& Crous (Halleen et al. 2004) and C. liriodendri JD MacDon.\& EE Butler, (MacDonald \& Butler 1981) were reported to be associated with the disease in New Zealand vineyards (Bleach et al. 2007). Symptoms include weak shoot growth, abnormal root development, necrotic root crowns, dark discolouration of vascular tissue and internal necrosis extending from the bark to the pith of affected rootstocks. The primary source of inoculum is the soil and infection is usually via the roots and basal end of the trunk. Research has shown that all rootstock varieties commonly used in New Zealand vineyards are susceptible to Cylindrocarpon spp. (Jaspers et al. 2007).

Arbuscular mycorrhizae (AM) are believed to suppress infection by root pathogens mainly through competition with the pathogens for infection points on the roots (Muchovej 2004). Results from studies carried out in California (Gubler \& Petit 2006) suggested that preplant applications of AM may reduce BF disease in the nursery and in the vineyard. This greenhouse experiment at Lincoln University investigated colonisation of six common rootstocks by two mycorrhizal species, G. mosseae and A. laevis, and their potential to protect against BF disease. Field experiments in both Auckland and Marlborough tested the effectiveness of mycorrhizae compared with four other soil treatments to enhance establishment of young rootstock plants. 


\section{MATERIALS AND METHODS}

\section{Greenhouse experiment}

Callused cuttings of six rootstock varieties, 101-14, 3309, 420A, 5C, Riparia Gloire and Schwarzmann, were planted into a soil-free potting mix deficient in phosphorus in 2.5 litre plastic containers and laid out in a randomised design, with six replicates for each treatment combination. The six rootstocks were inoculated with $G$. mosseae or A. laevis, 150 spores per vine, as previously described (Brundrett et al. 1996). The plants were grown for 7 months and the root samples were assessed for mycorrizal colonisation by staining with trypan blue followed by microscopic examination, as previously described (Brundrett et al. 1996). The plants were then inoculated with $60 \mathrm{ml}$ of a mixed conidial suspension $\left(10^{6} / \mathrm{ml}\right)$ of $C$. destructans, $C$. macrodidymum and $C$. liriodendri. The plants were grown in a greenhouse and harvested 5 months after inoculation with Cylindrocarpon spp. Initially, the experimental design included pathogen free control plants for each of the three treatments (no mycorrhizae, G. mosseae only, A. laevis only). However, it soon became apparent that splash dispersal during watering had resulted in all treatments being infected with Cylindrocarpon spp. As the amount of inoculum was not consistent, the pathogen free controls were removed from the analysis.

\section{Field experiment}

Rootstock cuttings of 101-14 and 5C were planted into trays of pumice and placed on heat pads at $25^{\circ} \mathrm{C}$ for 5 weeks to develop calli. For the AM treatment, the cuttings were inoculated by adding AM spores (200 spores of each species per litre) to the pumice. A sample of roots was taken from these plants to verify AM colonisation.

The field sites in Blenheim and Auckland were previously used as grapevine nurseries and known to be infested with Cylindrocarpon spp. They had also been inoculated for an experiment the previous year with $20 \mathrm{ml}$ of $C$.destructans, $C$. macrodidymum and C. liriodendri (mixed conidia, $10 \% \mathrm{ml}$ ) injected at 24 positions $/ \mathrm{m}^{2}$ to a depth of about $15 \mathrm{~cm}$ giving a conidia concentration of $4.8 \times 10^{8}$ conidia/ $\mathrm{m}^{2}$. Prior to planting the soils were cultivated, thereby mixing the remaining inoculum (if any) through the site. In Blenheim the same site was used as before but in Auckland movement of a fence led to misdirection, and the experimental site was later found to be adjacent to and about $3 \mathrm{~m}$ from the initially inoculated soil. Therefore, inoculum levels were expected to be lower than in Blenheim but no soil plating was done to determine inoculum levels.

Planting was done in late October 2006 in Auckland and mid November in Blenheim. One month prior to planting, four soil treatments were applied. These were two soil fumigants, (1) Telone C35 (soil fumigant), (2) Chloropicrin (soil fumigant), both applied by contractors, and two soil amendments, (3) active compost at $40 \mathrm{~kg} / \mathrm{m}^{2}$ and (4) WormTech ${ }^{\mathrm{TM}}$ liquid at 5 litres $/ \mathrm{m}^{2}$. Other treatments were (5) untreated soil and (6) untreated soil with AM treated rootlings. The treatments were replicated six times. The two rootstock varieties were planted as subplots. Within this layout, each sub-plot had a double row of six plants of which the centre eight were assessed and the end plants treated as buffers $(6 \times 6 \times 2 \times 8=576$ plants assessed $)$. The plants were set out in a randomised split plot design, planted according to standard nursery practices, grown for 8 months and then harvested.

\section{Harvest}

For both greenhouse and field experiments, grapevine root and shoot dry weight (DW) was recorded. The plant trunks were surface-sterilised, dissected and segments of the basal trunk tissue transferred to potato dextrose agar (Oxoid) as described by Halleen et al. (2003). After $7-10$ days incubation at $20^{\circ} \mathrm{C}$, Cylindrocarpon spp. growing from the plant tissue were identified morphologically and results recorded.

\section{Statistical analysis}

In the greenhouse experiment, incidence of infection by Cylindrocarpon spp. data for the three treatments (A laevis + Cylindrocarpon, G. mosseae $+C y l i n d r o c a r p o n$ and Cylindrocarpon only) were back transformed prior to analysis using the generalized linear mixed model (GLMM) to compare disease incidence. All other data were analysed by analysis of variance (ANOVA) using Genstat 9. Comparison of means was conducted with Fishers protected least significant difference (LSD) test at $\mathrm{P}<0.05$. 


\section{RESULTS AND DISCUSSION}

Greenhouse experiment

Table 1 shows that the six rootstocks had very different responses to inoculation with $\mathrm{AM}$ and that these responses were variable depending on the specific AM and rootstock combination $(\mathrm{P}<0.05)$. Shoot DW was significantly improved by inoculating $101-14$ with AM, although only A. laevis also improved root DW for this rootstock variety. For rootstock 3309, only G. mosseae improved shoot DW, whereas both AM increased root DW. In contrast, for rootstock $420 \mathrm{~A}$ only A. laevis increased both root and shoot DW. For rootstocks 5C, Riparia Gloire and Schwarzmann, inoculation with G. mosseae significantly increased shoot DW, although the increased shoot mass induced by this AM was only associated with increased root DW in 5C and Riparia Gloire. However, the effect of A. laevis was quite different, with significantly decreased shoot DW of 5C, Riparia Gloire and Schwarzmann, and decreased root DW of Riparia Gloire and Schwarzmann. The percentage infection by Cylindrocarpon spp. was not significantly different between treatments $(\mathrm{P}=0.883)$ or between rootstocks $(\mathrm{P}=0.057)$, even though the values for rootstocks $3309(0.1 \%)$ and Riparia Gloire $(0.3 \%)$ were very low. The low values for Riparia Gloire and 3309 were primarily due to a complete absence of infection in the G. mosseae treatment.

TABLE 1: Shoot and root dry weights (g DW/plant) for grapevine rootstocks inoculated with Cylindrocarpon spp. with or without arbuscular mycorrhizae (Glomus mosseae or Acaulospora laevis) and mean incidence of Cylindrocarpon infection (\%) of rootstocks across all treatments.

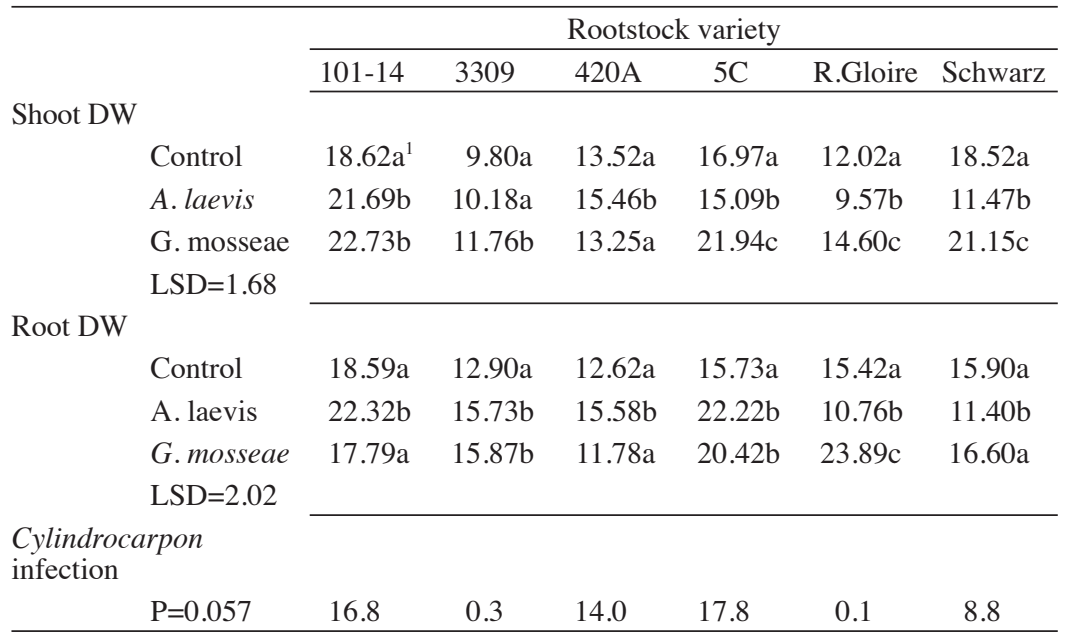

${ }^{1}$ Means for the shoot or root DW sharing the same letters are not significantly different at $\mathrm{P}<0.05$.

Grapevine rootstocks are well known for their different biological traits and variable colonisation by AM (Schreiner 2003). Studies on the ability of AM to reduce the deleterious effects of soil-borne pathogens have also shown that these effects vary with the plant host and AM combination (Azcón-Aguilar \& Barea 1996). In this study, grapevine rootstocks inoculated with AM showed some variation in their resistance to infection by Cylindrocarpon spp. Generally, G. mosseae had a greater beneficial effect than A. laevis across all rootstocks, and only A. laevis had a negative effect on the growth 
of some rootstocks. In similar work, Petit \& Gubler (2006) showed that inoculation with G. intraradices decreased disease severity in grapevines infected by Cylindrocarpon spp. The mechanisms by which AM protect plants against soil-borne pathogens is poorly understood, but is thought to include increasing nutrient uptake, competition for infection sites and changes to root ultrastructure (Azcón-Aguilar \& Barea 1996). In this study the AM associations improved plant growth, although the exact mechanism by which this occurred is unclear.

\section{Field experiment}

The soil treatments for the Auckland and Blenheim experiments did not significantly reduce Cylindrocarpon infection incidence $(\mathrm{P}>0.05)$ of the rootstock plants nor were any differences seen between varieties $(\mathrm{P}>0.05)$. In Blenheim approximately $30 \%$ of the plants died due to hot, dry conditions after planting and were replaced within 4-5 weeks of the initial planting. Early plant survival data were not recorded for the Auckland site. At harvest, only plants with both roots and shoots were classified as live plants. Survival of plants for the mycorrhizal (57\%), Telone C35 (45\%) and control (49\%) treatments were significantly different, and these levels were consistent between the two rootstocks. AM are known to alleviate drought stress and this effect is thought to be variable between AM species and isolates (Augé 2001). In the present research, inoculation of rootstocks with A. laevis and G. mosseae seemed to have increased survival during the drought conditions experienced in Blenheim, as reported by Salinger $(2006,2007)$, who described significant soil moisture deficits (more than $110 \mathrm{~mm}$ and $130 \mathrm{~mm}$ ) that had persisted in central Marlborough in 2006 and 2007 respectively. However, it is unclear whether the effect in the present research was attributable to one of the AM species or the combination. Future experiments could address the relative effect of each AM species on increasing drought tolerance in grapevines.

All of the 576 plants harvested from each site were assessed, of which $85 \%$ were alive in Auckland and $73 \%$ in Blenheim (Figures $1 \& 2$ ). The disease incidence for Auckland plants was low $(<25 \%)$ compared to Blenheim plants $(>50 \%)$, probably because of the lower soil inoculum, since they were planted alongside and not in the site that had been inoculated with Cylindrocarpon spp. the previous year. The treatments at both these sites did not have a significant effect on Cylindrocarpon incidence, although there were large differences between some treatments. For example, there was a trend $(\mathrm{P}=0.13)$ for the fumigants chloropicrin and Telone $\mathrm{C} 35$ to reduce Cylindrocarpon incidence by 16 and $17 \%$ respectively, in Blenheim and by 24 and 42\%, respectively, in Auckland $(\mathrm{P}=0.096)$, compared with the untreated control. Of the biological treatments, only the Wormtech $^{\mathrm{TM}}$ product caused a trend for reducing Cylindrocarpon incidence (by $30 \%$; $\mathrm{P}=0.13$ ) and only in the Blenheim site.

The dry weight assessments indicated significant $(\mathrm{P}<0.05)$ effects of the treatments on plant growth at the Auckland site (Fig. 1), with AM causing far greater increases in root DW (214\%), relative to the control, than that recorded for the WormTech ${ }^{\mathrm{TM}}(26 \%)$ and active compost $(42 \%)$ treatments. In Blenheim, there were no significant treatment effects $(\mathrm{P}>0.05)$, although there were some trends with mycorrhizal colonisation and Telone C35 treatments, both causing 9\% increased root DW (Fig. 2). The overall trends in shoot weights tended to reflect those of the root weights. Clearly precolonisation of rooted cuttings prior to planting led to an increased root mass, which is likely to contribute to better establishment of these plants in the field. The rootstocks used in the field trial were 101-14 and 5C, which had responded well to both A. laevis and G. mosseae in the greenhouse trials. The field soil will also have contained AM spores and future research could determine whether colonisation by field AM was stimulated or out-competed by the inoculated strains. 


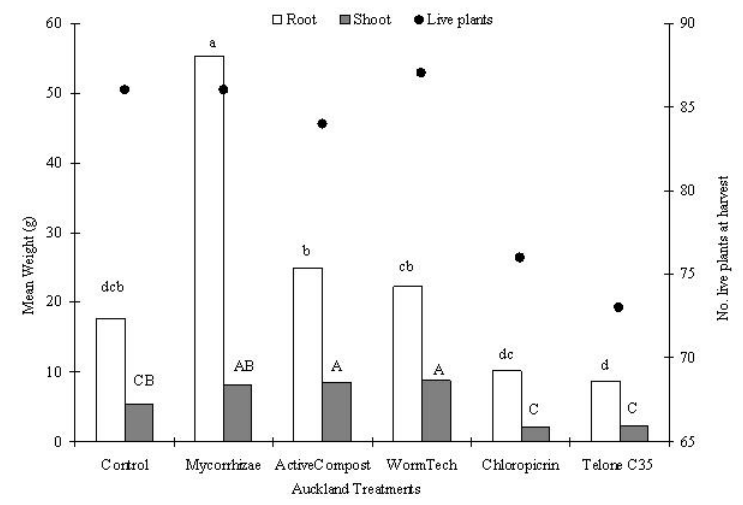

FIGURE 1: Mean root and shoot dry weights and the number of live plants in the Auckland field experiment. Means with the same letter are not significantly different $(\mathbf{P}<0.001)$.

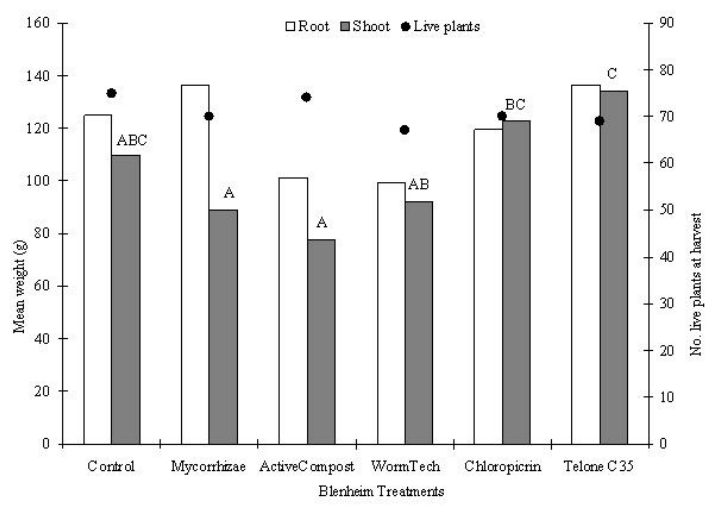

FIGURE 2: Mean root and shoot dry weights and the number of live plants in the Blenheim field experiment. Shoot means with the same letter are not significantly different $(\mathrm{P}<0.05)$. Root means were not significantly different $(\mathbf{P}>\mathbf{0 . 0 5})$.

\section{CONCLUSION}

The greenhouse experiment showed that plants colonised by AM had improved vigour, with the extent of the effect being specific for particular rootstock and AM combinations. These data indicate that the relationship between the plant and symbiont is complex and can be influenced by the traits of individual cultivars. Future research could investigate changes in the mycorrhizosphere to elucidate the mechanism by which Cylindrocarpon spp. are inhibited and whether these and other AM species can protect against other soil-borne diseases. In addition, it would be useful to know whether the different AM species can exhibit synergy or whether they compete with each other for the ecological niche, with one or some species preferentially colonising the roots. 
The field experiments indicated that plants colonised by AM had dramatically increased root mass over other treatments. Increased root mass is likely to contribute to better establishment and healthier plants that have a greater ability to withstand environmental stressors such as drought. The experiments demonstrated that, not only are AM a realistic option for control of BF disease, they can also contribute to greater health of young plants under field conditions.

\section{ACKNOWLEDGEMENTS}

Thanks to New Zealand Winegrowers for funding this project; Corbans Viticulture and Pernod Ricard (Fairhall Nursery) for providing plants, assistance and nursery sites; and WormTech ${ }^{\mathrm{TM}}$ NZ Ltd, Living Earth and Leicester's Fumigation Ltd for supply and assistance with application of their products.

\section{REFERENCES}

Augé RM 2001. Water relations, drought and vesicular-arbuscular mycorrhizal symbiosis. Mycorrhiza 11: 3-42.

Azcón-Aguilar C, Barea JM 1996. Arbuscular mycorrhizas and biological control of soil-borne plant pathogens - an overview of the mechanisms involved. Mycorrhiza 6:457-464.

Bleach CM, Jones EE, Jaspers MV 2007. Survey for back foot disease in New Zealand vineyards. 13th Annual Conference, Romeo Bragato. New Zealand Winegrowers, Ellerslie Event Centre, Auckland, New Zealand. Pp. 143-146.

Brundrett M, Bougher N, Dell B, Grove T, Malajczuk N 1996. Working with Mycorrhizas in Forestry and Agriculture, Australian Centre for International Agricultural Research, Canberra, Australia.

Dodd JC, Boddington CL, Rodriguez A, Gonzalez-Chavez C, Mansur I 2000. Mycelium of arbuscular mycorrhizal fungi (AMF) from different genera: form, function and detection. Plant and Soil 226: 131-151.

Gubler WD, Petit E 2006. Influence of Glomus intraradices on black foot disease caused by Cylindrocarpon macrodidymum on Vitis rupestris under controlled conditions. Plant Disease 90: 1481-1484.

Halleen F, Crous PW, Petrini O 2003. Fungi associated with healthy grapevine cuttings in nurseries, with special reference to pathogens involved in the decline of young vines. Australasian Plant Pathology 32: 47-52.

Halleen F, Schroers H-J, Groenewald JZ, Crous PW 2004. Novel species of Cylindrocarpon (Neonectria) and Campylocarpon gen. nov. associated with black foot disease of grapevines (Vitis spp.). Studies in Mycology 50: 431-455.

Jaspers MV, Bleach CM, Harvey IC 2007. Susceptibility of grapevine rootstocks to Cylindrocarpon disease. Phytopathologia Mediterranean 46: 102-128.

MacDonald JD, Butler EE 1981. Cylindrocarpon root rot of tulip poplar. Plant Diseases 65: 154-157.

Muchovej RM 2004. Mycorrhizae are necessary elements for healthy vegetable crops. American Vegetable Grower, 1 December.

Salinger J. 2006. NIWA National Climate Centre. New Zealand national climate summary - the year 2006. http://www.niwa.cri.nz/__data/assets/pdf_file/0016/30742/ aclimsum_06.pdf (accessed on 03/06/2008).

Salinger J. 2007. NIWA National Climate Centre. New Zealand national climate summary - the year 2007. http://www.niwa.cri.nz/__data/assets/pdf_file/0006/63879/ aclimsum_07.pdf (accessed on 03/06/2008).

Schreiner RP 2003. Mycorrhizal colonization of grapevine rootstocks under field conditions. American Journal of Viticulture 53:143-149 